\title{
Is asthma in the elderly different? Functional and clinical characteristics of asthma in individuals aged 65 years and older
}

\author{
Elena Curto ${ }^{1}$, Astrid Crespo-Lessmann ${ }^{1 *}$ (D), María Victoria González-Gutiérrez², Santiago Bardagi², \\ Concepción Cañete ${ }^{3}$, Concha Pellicer ${ }^{4}$, Teresa Bazús ${ }^{5}$, María del Carmen Vennera ${ }^{6}$, Carlos Martínez ${ }^{7}$ and \\ Vicente Plaza'
}

\begin{abstract}
Background: The prevalence of chronic diseases in the elderly (> 65 years), including asthma, is growing, yet information available on asthma in this population is scarce.

Our objective is to determine the differential clinical and functional characteristics of the population $>65$ years old with asthma included in the Integrated Research Programs of Asthma Databank of the Spanish Society of Pneumology and Thoracic Surgery (www.bancodatosasma.com).

Methods: Retrospective comparative descriptive study of demographic, clinical and functional variables for 1713 patients with asthma categorized into 3 age groups as follows: adults aged $<65$ years (A), younger elderly aged 6574 years (B) and older elderly aged $\geq 75$ years (C).

Results: Predominant features of elderly patients with asthma $(N=471)$ were the female sex, fewer smokers, greater obesity, poorer lung function, and lower values of nitric oxide in exhaled air $(p<0.01)$. The most frequently associated comorbidity was gastroesophageal reflux. The highest doses of inhaled corticosteroids were by group A (60.8\%). For the sample overall, 23.2\% ( $N=398)$ were being treated with omalizumab and 8.2\% $(N=140)$ were corticosteroid-dependent (10.6\% in group B). The highest percentage of patients receiving antileukotriene agents was in group B (42.9\%).
\end{abstract}

Conclusions: Asthma in adults aged $>65$ is more severe and associated with greater comorbidity, which would indicate the need for a more integrated and multidimensional approach to asthma treatment for these patients.

Keywords: Asthma, Elderly, Age, Phenotypes, Adults

\section{Backgrounds}

Greater life expectancy has led to a remarkable increase in the prevalence of chronic diseases. According to the Spanish National Institute of Statistics (INE), the percentage of the population over 65 years of age, which currently stands at $18.2 \%$, will be $24.9 \%$ in 2029 and $38.7 \%$ in 2064 [1]. Asthma has conventionally been

\footnotetext{
* Correspondence: acrespo@santpau.cat

'Servicio de Neumología, Hospital de la Santa Creu i Sant Pau, Institut d'Investigació Biomédica Sant Pau, Carrer Mas Casanovas 90, 08041 Barcelona, Spain

Full list of author information is available at the end of the article
}

considered a disease of children and young adults, but population ageing has led to a growing interest in the study of asthma in older people, as it is suspected that asthma prevalence may be underestimated [2], asthmarelated morbidity and mortality may be greater [3] and socioeconomic and health costs are higher [4] in older population segments.

Little information is available in the specialized literature on the pathophysiological mechanisms that determine asthma-related airway inflammation in the elderly, but it is suspected that they may be different from the mechanisms at work in younger people [5]. Immunosenescence as 
described in the elderly [6] encompasses innate and adaptive changes in the immune response as a consequence of normal ageing. It can be assumed that this natural process combines with immune changes in the airways and comorbidities associated with advancing age to define the characteristics and particular phenotypes of elderly patients with asthma [7]. Some of these immunobiological characteristics are beginning to be known, but to date, almost exclusively from small studies $[8,9]$.

Older patients with asthma have a greater number of comorbidities, including obesity and gastroesophageal reflux (GERD) [10]. An added complication in the management of asthma is the concomitant use of treatments for comorbidities, along with possible technical difficulties in handling inhalers [11]. These patients are also likely to be underdiagnosed, due to factors such as a tendency to minimize symptoms [12], technical difficulties in performing spirometry diagnoses [13-15], and a lack of adapted reference values for functional test results [16].

This study was undertaken with the objective of determining possible differences in the clinical and functional characteristics of 3 groups -- older adults, younger elderly, and older elderly - with asthma.

\section{Methods}

In this comparative retrospective study, data for all patients included from January 2008 to December 2013 in the asthma database of the Integrated Research Pro gramme (PII) of the Spanish Society of Pneumology and Thoracic Surgery (SEPAR) (www.bancodatosasma.com) were extracted for descriptive analysis. Pulmonologists and allergists from seven Spanish centres (Hospital de la Santa Creu i Sant Pau, Hospital de Mataró, Hospital Francesc de Borja, HU Central de Asturias, Hospital Clínic, Hospital General de l'Hospitalet) contributed to this database with data on their outpatients, entered non-consecutively and when considered appropriate.

Analysed were demographic and clinical variables; disease control variables using the asthma control test (ACT) questionnaire [17]; number of hospital admissions in the previous year; oral corticosteroid treatment; therapeutic adherence (defined by the treating physician as good/fair/ poor); functional variables (fraction of exhaled nitric oxide $\left(\mathrm{F}_{\mathrm{e}} \mathrm{NO}\right.$ following the 2005 recommendations of the American Thoracic Society/European Respiratory Society [41]) and forced expiratory volume in the first second $\left.\left(\mathrm{FEV}_{1}\right)\right)$; and the treatment received. Comorbidities were self-reported by the patients.

Difficult-to-control asthma was defined as asthma that was insufficiently controlled despite an appropriate therapeutic strategy adapted to severity level [18]. Poorly controlled asthma was defined according to SEPAR guidelines [19] in force at the time of data collection and an ACT questionnaire score of $<20$. The cut-off point of
$<30$ parts per billion (ppb) was used as reflecting normal $\mathrm{F}_{\mathrm{e}} \mathrm{NO}$ values according to guidelines in force at the time of data collection [20]. Low, intermediate and high daily doses of inhaled corticosteroids -- beclomethasone propionate or equivalent -- were defined as $<500 \mu \mathrm{g}$, $500 \mu \mathrm{g}-1000 \mu \mathrm{g}$ and $>1000 \mu \mathrm{g}$, respectively. Adherence was defined as good, fair or poor according to the doctor's criteria and the asthma education of the patient was similarly defined.

The study population of older adults was categorized into three population groups, as follows: < 65 years (group A, older adults), 65-74 years (younger elderly, group B), and $\geq 75$ years (older elderly, group C) [21].

\section{Statistical analysis}

Descriptive baseline values are reported as percentages and frequencies for the qualitative data and as means and standard deviations for the quantitative data. Categorical variables are described by contingency tables and using the chi-square test for the number and percentages of cases. Descriptive analysis was by age group and categorized by age. The level of statistical significance was set to $5 \%(\alpha=0.05)$ and SPSS (version 19.0) for Windows (SPSS, Inc., Chicago, Il, USA) was used for the statistical analysis.

\section{Results}

A total of 1713 patients were analysed: 1242 (72.5\%) aged < 65 years (group A), 282 (16.5\%) aged 65-74 (group B), and 189 (11\%) aged $\geq 75$ years (group C).

\section{Sample characteristics}

The overall sample $(N=1713)$ was predominated by women $(68 \% ; N=1172)$ and mean body mass index (BMI) was $28.05 \mathrm{~kg} / \mathrm{cm}^{2}$ (around a third (30\%; $N=505$ ) had a BMI greater than $30 \mathrm{~kg} / \mathrm{cm}^{2}$ ). Of the sample, 14.3\% $(N=245)$ had difficult-to-control asthma, and $71.7 \%(N=1121)$ had allergic sensitization as demonstrated by the prick-test and/or specific immunoglobulin E (IgE). Regarding smoking habits, $63.8 \%$ of the sample $(N=1049)$ were non-smokers, $22.7 \%(N=373)$ were ex-smokers, $8.6 \%(N=142)$ were light smokers, $2.9 \%$ $(N=47)$ were passive smokers, and $1.9 \%(N=32)$ were heavy smokers (more than 16 cigarettes/day according to the WHO (2003) definition).

Almost half $(49.1 \%, N=841 / 1615)$ of patients with asthma had rhinosinusitis and $16.5 \%(N=208 / 1713)$ had nasal polyposis. Other comorbidities were GERD (66.5\%; $N=123 / 185$ ), followed by sleep apnea-hypopnea syndrome (OSA) (14.1\%; $N=26 / 185)$, fibromyalgia (9.7\%; $N=18 / 185$ ), and inflammatory bowel disease (IBS) $(1.1 \% ; \mathrm{N}=2 / 185)$.

Current occupation (previous occupation for retired patients) was recorded for $48.6 \%$ of the sample $(N=$ 
$833 / 1713)$, over half of whom (56\%; $N=471 / 883)$ were/ had been employed in high-risk occupations, mainly in the textile industry $(N=112 / 833)$, cleaning sector $(N=$ $106 / 833)$, and agriculture $(N=31 / 833)$.

Nearly two thirds of the patients $(63.1 \% ; N=1063$ / 1684) had poor disease control according to the ACT questionnaire. Although most of the patients (87.2\%; $N=1494 / 1713$ ) had not required hospitalization in the previous year, $3.8 \%$ had previously been admitted more than once. Just over half (55\%; $N=830 / 1495)$ of the patients had not received any systemic corticosteroid treatment for exacerbations, whereas $29.23 \%$ of patients had received this treatment more than twice in the previous year.

Regarding maintenance treatment, the most common inhaled corticosteroid at baseline was budesonide (54\%; $N=935 / 1713)$, usually at intermediate doses (49\%), and the most typical long-acting beta adrenergic agonist (LABA) was formoterol (46.9\%; $N=803 / 1713)$. As adjuvant therapies, $33.9 \%$ of the sample were being treating with antileukotriene agents, $4.5 \%$ with theophylline, $23.2 \%$ with omalizumab, $0.6 \%$ with immunotherapy, and $8.2 \%$ with fixed-dose oral corticosteroids.

Treatment adherence was rated as good (70.9\%), poor $(13.8 \%)$ or fair $(5.2 \%)$ by attending physicians at the time of data collection, and $60.2 \%(N=889 / 1476)$ were considered to have received some type of asthma education. As for lung function, 74.5\% had $\mathrm{FEV}_{1}>65$ and $9.2 \%$ had $\mathrm{FEV}_{1}<50 \%$.

\section{Characteristics by age group}

Table 1 summarizes the clinical and functional characteristics (with statistical significance values) for the 3 age groups: older adults (group A), younger elderly (group
B) and older elderly (group C). Women predominated in the 3 groups in similar proportions (although not to a statistically significant degree), obesity was higher in the 2 elderly groups ( $\mathrm{B}$ and $\mathrm{C}$ ), there were more smokers/ ex-smokers in the older adult group (A), and lung function was more impaired, whereas $\mathrm{F}_{\mathrm{e}} \mathrm{NO}$ values were lower, in the 2 elderly groups (B and $\mathrm{C}$ ).

Older adults (group A) received more cycles of oral corticosteroids $(70.9 \% \geq 2$ cycles in the previous year) and higher doses of inhaled corticosteroids andwere mainly treated with omalizumab $(76.8 \% N=337)$.

The diseases most frequently associated with the age groups (adjusted for age) were GERD, predominating in group C $(72.2 \%)$, OSA, predominating in group B (19.4\%), and fibromyalgia, predominating in group A (11\%).

\section{Discussion}

Our study demonstrates that asthma is clinically different in elderly patients. The fact that asthma severity and comorbidities are higher than in other adults needs to be taken into account to ensure multidimensional management when treating these patients.

In the past, asthma was considered predominantly a disease of childhood, but recent epidemiological studies indicate that it can affect people at any age, and is, in fact, very prevalent in the adult population (4.5-12.7\%) [22]. According to current demographic trends, a $100 \%$ increase in the number of people aged over 65 is expected in the coming decades [22, 23]. It would therefore be reasonable to assume that there will be an increase in the impact of asthma on older population segments in the near future.

Table 1 Characteristics of patients with asthma by age group

\begin{tabular}{|c|c|c|c|c|}
\hline Variable & $\begin{array}{l}\text { Group A: }<65 \text { years } \\
N=1240(72.5 \%)\end{array}$ & $\begin{array}{l}\text { Group B: } 65-74 \text { years } \\
N=282(16.5 \%)\end{array}$ & $\begin{array}{l}\text { Group C: } \geq 75 \text { years } \\
N=189(11 \%)\end{array}$ & $\mathrm{p}$ \\
\hline Sex $(\% \text { women })^{a}$ & $67.8 \%$ & $68.8 \%$ & $72.9 \%$ & 0.397 \\
\hline Active smokers $^{a}$ & $13.7 \%(N=163 / 1185)$ & $3.7 \%(N=10 / 272)$ & $0.5 \%(N=1 / 186)$ & $<0.001$ \\
\hline Ex-smokers $^{a}$ & $23.8 \%(N=282 / 1185)$ & $21.3 \%(N=58 / 272)$ & $17.7 \%(N=33 / 186)$ & $<0.001$ \\
\hline Obese $^{\mathrm{a}}\left(\mathrm{BMI}>30 \mathrm{~kg} / \mathrm{cm}^{2}\right)$ & $25.5 \%(N=299 / 1171)$ & $45.8 \%(N=125 / 273)$ & $44.3 \%(N=82 / 185)$ & $<0.001$ \\
\hline Diagnosed with difficult-to-control asthma ${ }^{a}$ & $15.3 \%(N=190 / 1240)$ & $14.2 \%(N=40 / 282)$ & $7.9 \%(N=15 / 189)$ & 0.027 \\
\hline $\mathrm{FEV}_{1}<50 \%^{\mathrm{a}}$ & $7.0 \%(N=74 / 1064)$ & $13.7 \%(N=34 / 249)$ & $16.7 \%(N=28 / 163)$ & $<0.001$ \\
\hline $\mathrm{FEV}_{1}<50 \%$ & $54.4 \%(N=74 / 136)$ & $25 \%(N=34 / 136)$ & $20.6 \%(N=28 / 136)$ & $<0.001$ \\
\hline $\mathrm{Fe}_{\mathrm{e}} \mathrm{NO}>30 \mathrm{ppb}$ & $89.9 \%(N=160 / 178)$ & $8.4 \%(N=15 / 178)$ & $1.7 \%(N=3 / 178)$ & $<0.001$ \\
\hline Received $\geq 2$ corticosteroid cycles in the previous year & $70.9 \%(N=310 / 437)$ & $19.7 \%(N=86 / 437)$ & $9.4 \%(N=41 / 437)$ & 0.106 \\
\hline Treated with high doses of inhaled corticosteroids ${ }^{b}$ & $60.8 \%(N=236 / 388)$ & $20.9 \%(N=81 / 388)$ & $18.3 \%(N=71 / 388)$ & 0.045 \\
\hline Treated with antileukotriene agents & $33 \%(N=387 / 1173)$ & $42.9 \%(N=115 / 268)$ & $27.8 \%(N=52 / 187)$ & 0.001 \\
\hline Treated with omalizumab & $76.4 \%(N=304 / 398)$ & $18.1 \%(N=72 / 398)$ & $5.5 \%(N=22 / 398)$ & 0.288 \\
\hline
\end{tabular}

Abbreviations: $B M I$ body mass index, $F_{e} N O$ fraction of exhaled of nitric oxide, $F E V_{1}$ forced expiratory volume in the first second

andicates analysed categorized by age group

b $>1000 \mu \mathrm{g} /$ day beclomethasone dipropionate or equivalent 
With respect to the general characteristics of the studied population $(N=1713)$, $68 \%$ were women; $27.5 \%$ were aged over 65 years; $63.8 \%$ were non-smokers; $49 \%$ had rhinosinusitis and $16.5 \%$ had nasal polyposis; $10.8 \%$ had comorbidities; $74.5 \%$ had $\mathrm{FEV}_{1}>65 \%$; $70.9 \%$ were good adherents to treatment; and $14.3 \%$ had difficult-to-control asthma and $63.1 \%$ showed poor asthma control $(\mathrm{ACT}<20)$. The high percentage of poor control is probably due to the fact that many patients were included on their first visit to the specialist, with poor control often being the very reason for referral. Furthermore, the high percentage of difficult-to-control asthma may be explained by the fact that many of the doctors who input the data were asthma specialists to whom severe cases were referred.

While better tools are available nowadays to measure therapeutic adherence by patients using inhalers, such as the test of adherence to inhalers (TAI) [24], electronic monitoring of prescribed medication collection and the use of electronics devices, at the time of creating the database these tools were not available. Adherence data was therefore compiled, as good, fair or poor, according to the doctor's criteria. While adherence for our sample was rated as good in $70.9 \%$ of the cases, this value is probably overestimated because the method used to assess adherence was the subjective opinion of the doctor.

Obesity, whose prevalence is increasing worldwide, represents a risk to the health of people at all ages, and not only because obese people are at an increased risk of asthma [25], but because they have more asthma symptoms, more frequent and serious exacerbations [26], poorer control [27], poorer response to various asthma medications [28], and a reduced quality of life [29]. However, because obesity causes significant changes in normal lung physiology (reduced expiratory reserve volume and, therefore, functional residual capacity), it has been demonstrated that obesity can be a confounder for a false diagnosis of asthma -- a fact which needs to be borne in mind in the diagnosis of asthma in obese individuals. Aaron et al. [30], for instance, in a prospective study of 540 patients with asthma diagnosed by a physician, subsequently assessed by spirometry with a bronchodilator test, methacholine challenge test and asthma treatment withdrawal, concluded that nearly a third (31.8\%) of obese people were wrongly diagnosed as having asthma. We found that the elderly patients with asthma in our sample were more prone to obesity, which, as a risk factor and an indicator of poor asthma control, would indicate the need for obesity to be taken into account in their therapeutic management. Also, it is important to consider that an important cumulative dose of corticosteroids will lead to weight gain, and higher risk of OSA, wich is even more important in elder patients with a longer asthma trajectory. In these patients, the symptoms of asthma combined with those of other comorbidities (like arthrosis, or congestive hearth failure) increase the risk of a sedentary lifestyle and therefore, overweight. Data on cardiovascular diseases and depression, which probably also play a role, were not collected in our study. The collected data from comorbidities of upper airway like rhinitis and nasal polyps are similar in general from those reported by Tiotiu et al [42] and other series. We did not collect data of vocal cord dysfunction, wich could also yield interesting results.

With respect to lung function, our study found that the elderly patients ( $>65$ years) had a poor pulmonary function, measured as $\mathrm{FEV}_{1}$. This result is of interest because, as is known, forced vital capacity (FVC) and $\mathrm{FEV}_{1}$ decrease with age from a maximum reached between 20 and 25 years [31]. This physiological decrease, combined with a poor pulmonary function, may alter symptoms and quality of life in elderly patients. Since forced vital capacity (FVC) data were not collected, the $\mathrm{FEV}_{1} / \mathrm{FVC}$ ratio could not be calculated. Given the high percentage of obesity observed in the elderly in our sample, this ratio would have allowed us to assess the presence or absence of obstruction so as to rule out mixed ventilatory impairment [32, 33].

With regard to the low $\mathrm{F}_{\mathrm{e}} \mathrm{NO}$ values in the elderly in our sample, this may be explained by the fact that the group of adults aged $<65$ years had a greater allergenic component, corroborated by the higher percentage being treated with omalizumab. Although some studies have found no differences in $\mathrm{F}_{\mathrm{e}} \mathrm{NO}$ values between patients with and without obesity [34], others have reported that obese people have higher $\mathrm{F}_{\mathrm{e}} \mathrm{NO}$ values to a statistically significant degree [35]. However, the fact that studies to date conducted in elderly populations have been based on small samples possibly explains the contradictory results [36-40]. In our study, patients $>65$ years old, despite having relatively higher obesity rates, had lower $\mathrm{F}_{\mathrm{e}} \mathrm{NO}$ values. This finding corroborates a study of $30 \mathrm{pa}-$ tients aged $\geq 65$ years with stable asthma followed up for a year with evaluations every 3 months, which found that $\mathrm{F}_{\mathrm{e}} \mathrm{NO}$ values were not elevated and did not correlate with demographics, comorbidities, treatment, symptoms or spirometry values. In fact, the suggestion by the authors of that study, that routine measurements of $\mathrm{F}_{\mathrm{e}} \mathrm{NO}$ values may not be clinically useful for elderly asthmatics [36], is corroborated by our results. Likewise, the fact that the elderly patients had a lower allergenic component may also have a bearing on their lower $\mathrm{F}_{\mathrm{e}} \mathrm{NO}$ values. However, while age itself may be a factor that could affect the cut-off point for a normal $\mathrm{F}_{\mathrm{e}} \mathrm{NO}$ value, perhaps its usefulness in the diagnosis and follow-up of these patients needs to be reassessed. 
Another aspect of interest is the economic burden of asthma in the elderly population. A study conducted by Plaza et al. [4] showed that the direct costs of managing asthma in the elderly were double those for non-elderly adults (an annual average of USD 1490 vs USD 773), mainly due to higher hospitalization and drug costs. Although our study did not assess asthma costs, the higher economic burden can be inferred from our results regarding greater disease severity and morbidity in the elderly in our sample.

The main strengths of this study are that the sample was large (1713 patients), the data were collected by asthma specialists, and many variables were analysed. As limitations, many variables were not completed by the professionals (because they did not have particular data or tests at their centre or due to a lack of time), the analysis was only transversal and descriptive, and the study may be biased by the fact that the sample may have had more severe asthma, given that the doctors who input the data were asthma specialists who more frequently treat more severe cases. Another fact not reflected in our data is that a diagnosis of asthma is generally recognized to be ruled out in a significant percentage of patients referred to an asthma unit. Finally, our analysis was based on a relatively old database (2008-2013) and therefore lacks certain information of current interest, such as objectively measured adherence to treatment (e.g., TAI, electronic prescription monitoring), and also excluded certain data that was not collected (such as years with asthma, phenotype classification, smoking-re lated factors, etc).

\section{Conclusion}

Our main result is that the functional and clinical characteristics of asthma in elderly patients ( $>65$ years) and older adults $(<65$ years $)$ are different, and that this difference should be borne in mind, along with age-related factors, in routine practice in order to achieve optimal disease control. Given that the fastest growing age band is the population aged $>65$ years, prospective studies are necessary to assess asthma behaviour and impact in the elderly.

\section{Acknowledgements}

All authors would like to thank Ailish M J Maher for their work in translating and reviewing the article.

\section{Funding}

Not applicable.

\section{Availability of data and materials}

The datasets generated during and/or analysed during the current study are not publicly available due to privacy policies but are available from the corresponding author on reasonable request. The data were registered in the asthma database of the Integrated Research Programme (PII) of the Spanish Society of Pneumology and Thoracic Surgery (SEPAR) (www. bancodatosasma.com). The access to this database is private for the members of SEPAR who request it with their user and password.

\section{Authors' contributions}

All the included authors collaborated with the design and collection of data for this study. AC and EC where the main contributors in writing the manuscript. All authors read and approved the final manuscript.

\section{Ethics approval and consent to participate}

This research project complies with the principles of the Declaration of Helsinki (18th World Medical Assembly, 1964). Patients were informed verbally and in writing, and they signed the informed consent before their inclusion in the study.

\section{Consent for publication}

Not applicable.

\section{Competing interests}

The authors declare that they have no competing interests.

\section{Publisher's Note}

Springer Nature remains neutral with regard to jurisdictional claims in published maps and institutional affiliations.

\section{Author details}

${ }^{1}$ Servicio de Neumología, Hospital de la Santa Creu i Sant Pau, Institut d'Investigació Biomédica Sant Pau, Carrer Mas Casanovas 90, 08041 Barcelona, Spain. ${ }^{2}$ Servicio de Neumología, Consorci Sanitari del Maresme, Carrer de Cirera 230, 08304 Mataró, Barcelona, Spain. ${ }^{3}$ Servicio de Neumología, Hospital General de l'Hospitalet, Av. Josep Molins 29, 08906 L'Hospitalet de Llobregat, Barcelona, Spain. ${ }^{4}$ Servicio de Neumología, Hospital Comarcal Francesc De Borja, Avinguda de la Medicina 6, 46702 Gandia, València, Spain. ${ }^{5}$ Servicio de Neumología, Hospital Universitario Central de Asturias, Av. Roma s/n, 3301 Oviedo, Spain. 'Servició de Neumología, Hospital Clinic de Barcelona, Carrer de Villarroel 170, 08036 Barcelona, Spain. ${ }^{7}$ Servicio de Neumología, Hospital Universitari Germans Trias i Pujol, Carretera de Canyet, s/n, 08916, Badalona, Barcelona, Spain.

Received: 30 November 2018 Accepted: 8 March 2019

Published online: 19 March 2019

\section{References}

1. Instituto Nacional de Estadística. Proyección de la Población de España 2014-2064. http://www.ine.es/prensa/np870.pdf. Accesed 27 Nov 2018.

2. Enright PL, McClelland RL, Newman AB, Gottlieb DJ, Lebowitz MD. Underdiagnosis and undertreatment of asthma in the elderly. Cardiovascular Health Study Research Group. Chest. 1999;1 16(3):603-13.

3. Moorman JE, Mannino DM. Increasing U.S. asthma mortality rates: who is really dying? J Asthma. 2001;38(1):65-71.

4. Plaza V, Serra-Batlles J, Ferrer M, Morejón E. Quality of life and economic features in elderly asthmatics. Respiration. 2000;67(1):65-70.

5. Murray MA, Chotirmall SH. The impact of Immunosenescence on pulmonary disease. Mediat Inflamm. 2015;2015:692546.

6. Thannickal VJ, Murthy M, Balch WE, Chandel NS, Meiners S, Eickelberg O, et al. Blue journal conference. Aging and susceptibility to lung disease. Am J Respir Crit Care Med. 2015;191(3):261-9.

7. Dunn RM, Busse PJ, Wechsler ME. Asthma in the elderly and late-onset adult asthma. Allergy. 2018;73(2):284-94.

8. Nyenhuis SM, Schwantes EA, Mathur SK. Characterization of leukotrienes in a pilot study of older asthma subjects. Immun Ageing. 2010;7(1):8.

9. Meyer KC. The role of immunity and inflammation in lung senescence and susceptibility to infection in the elderly. Semin Respir Crit Care Med. 2010; 31(5):561-74.

10. Zhu H, Pace F, Sangaletti O, Bianchi-Porro G. Features of symptomatic gastroesophageal reflux in elderly patients. Scand J Gastroenterol. 1993; 28:235-8.

11. Scichilone N, Braido F, Lavorini F, Levy ML, Usmani OS. Routine use of budesonide/formoterol fixed dose combination in elderly asthmatic patients: practical considerations. Drugs Aging. 2017;34(5):321-30.

12. Quadrelli SA, Roncoroni A. Features of asthma in the elderly. J Asthma. 2001;38(5):377-89.

13. Sherman CB, Kern D, Richardson ER, Hubert M, Fogel BS. Cognitive function and spirometry performance in the elderly. Am Rev of Respir Dis. 1993; 148(1):123-6. 
14. Bellia V, Pistelli R, Catalano F, Antonelli-Incalzi R, Grassi V, Melillo G, et al. Quality control of spirometry in the elderly. The SA.R.A. Study. SAlute respiration nell'Anziano $=$ respiratory health in the elderly. Am J Respir Crit Care Med. 2000;161(4):1094-100.

15. Pezzoli L, Giardini G, Consonni S, Dallera I, Bilotta C, Ferrario G, et al. Quality of spirometric performance in older people. Age Ageing. 2003:32(1):43-6.

16. Loth DW, Ittermann T, Lahousse L, Hofman A, Leufkens HG, Brusselle GG, et al. Normal spirometry values in healthy elderly: the Rotterdam study. Eur J Epidemiol. 2013;28(4):329-34

17. Vega JM, Badia X, Badiola C, López-Viña A, Olaguíbel JM, Picado C, et al. Validation of the Spanish version of the asthma control test (ACT). J Asthma. 2007;44(10):867-72.

18. López-Viña A, Agüero-Balbín R, Aller-Alvarez JL, Bazús-González T, Cosio BG, de Diego-Damiá A, et al. Normativa para el asma de control difícil. Arch Bronconeumol. 2005:41(9):513-23.

19. Cisneros C, Melero C, Almonacid C, Perpiña M, Picado C, Martínez-Moragón E, et al. Normativa SEPAR. Asma grave no controlada 2015. Arch Bronconeumol. 2015;51(5):235-46.

20. Moral VP. in representation of represent the coordinators, editors and reviewers of the GEMA ${ }^{4.0}$. Guía Española Para el Manejo del Asma (GEMA 2009). Guidelines for asthma management. Arch Bronconeumol. 2009; 45(Supl 2):1-35.

21. Orimo $H$, Ito $H$, Suzuki T, Araki A, Hosoi T, Sawabe M. Reviewing the definition of "elderly". Geriatr Gerontol Int. 2006;6:149-58.

22. Yáñez A, Cho SH, Soriano JB, Rosenwasser LJ, Rodrigo GJ, Rabe KF, et al. Asthma in the elderly: what we know and what we have yet to know. World Allergy Organ J. 2014;30:1-16.

23. Hanania NA, King MJ, Braman SS, Saltoun C, Wise RA, Enright $P$, et al. Asthma in the elderly: current understanding and future research needs: a report of a National Institute on Aging (NIA) workshop. J Allergy Clin Immunol. 2011;128:1-40.

24. Plaza V, Fernández-Rodríguez C, Melero C, Cosío B, Entrenas LM, Pérez de Llano L, al e. Validation of the 'test of the adherence to inhalers' (TAI) for asthma and COPD patients. J Aerosol Med Pulm Drug Deliv. 2016;29(2):142-52.

25. Peters U, Dixon AE, Forno E. Obesity and asthma. J Allergy Clin Immunol. 2018;141(4):1169-79.

26. Ahmadizar F, Vijverberg SJ, Arets HG, de Boer A, Lang JE, Kattan M, et al. Childhood obesity in relation to poor asthma control and exacerbation: a meta-analysis. Eur Respir J. 2016:48:1063-73.

27. Borrell LN, Nguyen EA, Roth LA, Oh SS, Tcheurekdjian H, Sen S, et al. Childhood obesity and asthma control in the GALA II and SAGE II studies. Am J Respir Crit Care Med. 2013;187(7):697-702.

28. Boulet LP, Franssen E. Influence of obesity on response to fluticasone with or without salmeterol in moderate asthma. Respir Med. 2007; 101(11):2240-7.

29. Van Gent $R$, van der Ent CK, Rovers MM, Kimpen JL, van Essen-Zandvliet LE, de Meer G. Excessive body weight is associated with additional loss of quality of life in children with asthma. J Allergy Clin Immunol. 2007;119(3): 591-6.

30. Aaron SD, Fergusson D, Dent $R$, Chen $Y$, Vandemheen $K L$, Dales RE. Effect of weight reduction on respiratory function and airway reactivity in obese women. Chest. 2004;125:2046-52

31. Knudson RJ, Lebowitz MD, Holberg Cl, Burrows B. Changes in the normal maximal expiratory flow-volume with growth and aging. Am Rev Respir Dis. 1983;127:725-34.

32. Quanjer PH, Stanojevic S, Cole TJ, Baur X, Hall GL, Culver BH, et al. Multiethnic reference values for spirometry for the 3-95-yr age range: the global lung function 2012 equations. Eur Respir J. 2012;40:1324-43.

33. Pérez-Padilla R, Valdivia G, Muiño A, López MV, Márquez MN, Montes de Oca $\mathrm{M}$, et al. Valores de referencia espirométrica en 5 grandes ciudades de Latinoamérica para sujetos de 40 o más años de edad. Arch Bronconeumol. 2006:42:317-25.

34. Kasteleyn MJ, Bonten TN, de Mutsert R, Thijs W, Hiemstra PS, le Cessie S, et al. Pulmonary function, exhaled nitric oxide and symptoms in asthma patients with obesity: a cross-sectional study. Respir Res. 2017;18:205.

35. Uppalapati A, Gogineni S, Espiritu JR. Association between body mass index (BMI) and fraction of exhaled nitric oxide (FeNO) levels in the National Health and nutrition examination survey (NHANES) 2007-2010. Obes Res Clin Pract. 2016;10(6):652-8.
36. Columbo M, Wong B, Panettieri RA, Rohr AS. Asthma in the elderly: the role of exhaled nitric oxide measurements. Respir Med. 2013;107(5):785-7.

37. Sfaxi I, Ben Saad H, Rouatbi S. Fraction of exhaled nitric oxide in healthy elderly Tunisian subjects. Nitric Oxide. 2015;50:88-97.

38. Godinho Netto ACM, Dos Reis TG, Matheus CF, Aarestrup BJV, Aarestrup FM Fraction of exhaled nitric oxide measurements in the diagnoses of asthma in elderly patients. Clin Interv Aging. 2016;11:623-9.

39. Jo EJ, Song WJ, Kim TW, Park HW, Chang YS, Kim TB, et al. Reference ranges and determinant factors for exhaled nitric oxide in a healthy korean elderly population. Allergy Asthma Immunol Res. 2014;6:504-10.

40. Hsu JY, Huang WC, Huang PL, Cheng YW, Chou MC. Usefulness of offline fractional exhaled nitric oxide measurements in the elderly asthmatic patients. Allergy Asthma Proc. 2013;34(5):434-8.

41. ATS/ERS Recommendations for Standardized Procedures for the Online and Offline Measurement of Exhaled Lower Respiratory Nitric Oxide and Nasal Nitric Oxide, 2005. American Journal of Respiratory and Critical Care Medicine 171 (8):912-930

42. Angelica Tiotiu, Davor Plavec, Silviya Novakova, Stefan Mihaicuta, Plamena Novakova, Marina Labor, Andras Bikov. Current opinions for the management of asthma associated with ear, nose and throat comorbidities. European Respiratory Review. 2018;27 (150):180056
Ready to submit your research? Choose BMC and benefit from:

- fast, convenient online submission

- thorough peer review by experienced researchers in your field

- rapid publication on acceptance

- support for research data, including large and complex data types

- gold Open Access which fosters wider collaboration and increased citations

- maximum visibility for your research: over $100 \mathrm{M}$ website views per year

At $\mathrm{BMC}$, research is always in progress.

Learn more biomedcentral.com/submissions 